\title{
DIFERENÇAS ENTRE LINHAGENS DE MILHO CULTIVADAS EM SOLUÇÃO NUTRITIVA QUANTO Â ABSORÇÃO E UTILIZAÇÃO DE NITROGÊNIO (')
}

\author{
ANGELA MARIA CANGIANI FURLANI $\left({ }^{2}\right)$, ONDINO CLEANTE BATAGLIA $\left(^{2}\right)$ \\ Q MARLENE LIMA $\left({ }^{3}\right)$
}

\begin{abstract}
RESUMO
Foram conduzidos dois ensaios em casa de vegetação, no período de outubro de 1982 a fevereiro de 1983, no Centro Experimental de Campinas, para o estudo diferencial de trinta e nove linhagens de milho (Zea mays $\mathrm{L}$.) quanto ao crescimento, absorção e utilização de $\mathrm{N}$, em soluçăo nutritiva. No primeiro ensaio, cinco linhagens foram cultivadas com $30,60,120,180$ e $240 \mathrm{mg} / \mathrm{litro}$ de $\mathrm{N}$, em vasos de 2,8 litros, até aos trinta dias de idade, a fim de se definir o nível mais adequado para diferenciação das plantas. No segundo ensaio, as linhagens foram selecionadas com $120 \mathrm{mg} /$ litro de N, no mesmo sistema de crescimento. Ambos os ensaios foram dispostos em blocos casualizados com quatro repetiçðes. As soluçðes nutritivas, continuamente arejadas, ño foram renovadas $\mathrm{e} o \mathrm{pH}$ foi periodicamente reajustado para o valor inicial $(5,0)$, durante os experimentos. Observaram-se diferenças entre as linhagens na produção de matéria seca da parte aérea e das rázes, nos teores de $\mathrm{N}$, nos conteúdos totais de $\mathrm{N}$ e nas relaçőes de eficiência (matéria seca produzida por unidade de $\mathrm{N}$ absorvida). A variação nos conteúdos totais de $\mathrm{N}(\mathrm{CV}$ das médias $=8,7 \%)$ foi correlacionada com os pesos de matéria seca total $(r=0,87)$. A variação nas relaçðes de eficiência (CV das médias $=16,1 \%$ ) também foi correlacionada com os pesos de matéria seca total $(r=0,92)$. Portanto, os processos de absorção e de utilização de $\mathbf{N}$ limitaram o desenvolvimento das plantas, sendo, entretanto, este último, o principal fator de variação entre as linhagens. Estas foram classificadas de acordo com a produção de matéria seca total em eficientes, medianamente eficientes e ineficientes.
\end{abstract}

Termos de indexaçăo: nitrogênio; milho; eficiência; absorçăo de $\mathrm{N}$; utilizaçăo de $\mathrm{N}$; solução nutritiva; seleção de plantas.

( ${ }^{1}$ ) Com auxílio da FINEP. Apresentado na XVI Reuniāo Brasileira de Fortilidude do Solo, Itabuna (BA), 22-27/7/84. Recebido para publicação em 12 de junho de 1984.

( $\left.{ }^{2}\right)$ Seção de Fertilidade do Solo e Nutriçảo de Plantas, IAC, CP 28, 13100 Campinas (SP). Com bolsa de suplementaç oxo do CNPq.

(') Seção de Genética, IAC. Com bolsa de suplementação do CNPq. 


\section{INTRODUÇÃO}

A necessidade crescente de aproveitamento de vastas extensões de solos subférteis e a constante elevação dos preços dos fertilizantes vêm despertando um interesse cada vez maior em alterar geneticamente as plantas no sentido de obter produções razoáveis em tais solos. Essa possibilidade se deve a inúmeras evidências que vêm sendo obtidas sobre variaçōes entre plantas, quanto à capacidade de absorver e utilizar nutrientes (BAKER et alli, 1970; CLARK \& BROWN, 1974; EPSTEIN \& JEFFERIES. 1964; GABELMAN, 1976; GERLOFF, 1976; HUCKLESBY et a1i. 197?, INDOREN et alii, 1977; NIELSEN \& BARBER, 1978; O'SULLIVA a alii. 1974 .

Plantas mais eficientes na absorção e utilização de nitrogêrio teriam, idealmente, sistemas radiculares bem desenvolvidos, maior capacidade de absorção e de translocação de $\mathrm{N}$ e maior eficiência de conversão metabólica do $\mathrm{N}$-mineral em $\mathrm{N}$-orgânico, em presença de teores mais baixos nos meios de crescimento. Num trabalho com sorgo (MARANVILLE et alii, 1980), foram avaliados doze hrbridos quanto à produção de matéria seca total por unidade de $\mathrm{N}$ absorvido (NE1), e de grãos por unidade de $\mathrm{N}$ absorvido (NE2), e o produto de NE2 pela relação do conteúdo de $\mathrm{N}$ no grão e na palha (NE3). Detectou-se uma diferença de $20 \%$ entre o melhor e o pior hibrido para o parâmetro NE1. Entretanto, a distribuição de N no grão e na patha foi o fator que apresentou diferenças mais marcantes entre os híbridos. Salientaram-se também variaçōes anuais de comportamento devidas à influência do meio ambiente.

Poucos trabalhos têm sido desenvolvidos com milho nesse sentido, mas evidências de diferenças genéticas na absorção, transiocação e/ou distribuição de $\mathrm{N}$ na planta têm sido obtidas por alguns pesquisadores

Diferenças altamente significativas na capacidade geral e especifica de combinação de dez linhagens de milho duro com nove linhagens de dentado quanto à absorção de $\mathrm{N}$ em diferentes fases de crescimento e quanto a sua translocação foram observadas por POLLMER et alii (1979). Em função desses resultados, os autores postularam que os híbridos com alta produção de grãos e alta porcentagem de proteína possuiriam alta taxa de absorção de $\mathrm{N}$, uma fase mais longa de absorção e alta capacidade de sua translocação Entretanto, salientaram que a importância desses fatores pode variar com diferentes genótipos e com o meio ambiente.

Em milheto, observaram-se diferenças significativas entre cultivares na habilidade de utilização de $N$, para crescimento e produção de grãos, mas não se observaram diferenças significativas na absorção de $\mathrm{N}$ (ALAGARSWAMY \& BIDINGER, 1982). 
Em solução nutritiva, foram determinadas diferenças entre genótipos de sorgo, na produção de matéria seca, na absorção, distribuição e utilização de $\mathrm{N}$ em diferentes idades da planta (FRANÇA, 1983). Quarenta e quatro genótipos foram selecionados, com baixo nível de $\mathrm{N}$, sendo observadas respostas diferenciais com variações de $131 \%$ na produção de matéria seca, $75 \%$ no conteúdo de $\mathrm{N}, 59 \%$ na relação entre o conteúdo de $\mathrm{N}$ da parte aérea e das raízes, e $34 \%$ na matéria seca por unidade de $\mathrm{N}$ absorvido.

O estudo em solução nutritiva traz vantagens no sentido de poder controlar as condições de crescimento das plantas, estudar o desenvolvimento do sistema radicular e comparar um número relativamente grande de genótipos num curto espaço de tempa Torna-se essencial, entretanto, a obtenção de dados comparativos em solo para concluir se a técnica em solução nutritiva pode ser usada como ferramenta auxiliar na seleção e melhoramento de plantas, quanto às características nutricionais

Este trabalho tem por objetivo definir condições de crescimento em solução nutritiva e estudar o comportamento de linhagens de milho, quanto à absorção e utilização do $\mathrm{N}$, em baixos níveis, mediante medição da produção de matéria seca da parte aérea e das raízes, do teor de $\mathrm{N}$ nas partes da planta, do conteúdo total de $\mathrm{N}$ nas plantas e da produção de matéria seca total por unidade de $\mathrm{N}$ absorvido, em plantas jovens.

\section{MATERIAL E MÉTODOS}

\section{Ensaio com cinco linhagens de milho, em solução nutritiva, com diferen- tes niveis de $\mathbf{N}$}

O ensaio foi conduzido em casa de vegetação, no período de outubro a novembro de 1982, no Centro Experimental de Campinas. Utilizaram-se vasos de 2,8 litros (caixas plásticas com tampa), revestidos de folha de alumínio. As tampas foram pintadas com tinta prateada e furadas: um furo central de cerca de $2,5 \mathrm{~cm}$ de diâmetro e um lateral de cerca de $0,5 \mathrm{~cm}$ de diâmetro. No furo central, foi introduzida uma plântula sustentada e protegida por uma tira de esponja ao redor do caulículo. O furo lateral recebeu um tubo de aeração. As sementes de milho foram germinadas em rolos de papel de germinação e as plântulas, com sete dias de idade, foram transplantadas para os vasos, contendo solução nutritiva com $30,60,120,180$ e $240 \mathrm{mg} /$ litro de N. Utilizaram-se as linhagens seguintes: IA 2876.3.1.2.3; 11.19.3.3; 10.11.1.1; 11.21.1. 1 e 11.1.3.1. 
No quadro 1 , acha-se a composição das soluções nutritivas, cujo $\mathrm{pH}$ foi ajustado para 5,0 , registrado periodicamente e reajustado para o valor inicial, três vezes por semana, com solução de $\mathrm{H}_{2} \mathrm{SO}_{4} 0,1 \mathrm{~N}$.

QUADRO 1 - Composição das soluçðes nutritivas utilizadas nos ensaios

\begin{tabular}{|c|c|c|c|c|c|}
\hline \multirow{2}{*}{ Elemento $\left({ }^{1}\right)$} & \multicolumn{5}{|c|}{ Tratamentos (Niveis de $\mathrm{N}$ ) } \\
\hline & 1 & 2 & 3 & 4 & $\overline{5}$ \\
\hline & \multicolumn{5}{|c|}{ - Miligrama do elemento/litro soluçăo } \\
\hline $\mathrm{N}-\mathrm{NO}_{3}^{-}$ & 26,7 & 53,3 & 106,7 & 160,0 & 213,3 \\
\hline $\mathrm{N}-\mathrm{NH}_{4}^{+}$ & 3,3 & 6,7 & 13,3 & 20,0 & 26,7 \\
\hline $\mathrm{Ca}$ & 200,0 & 200,0 & 200,0 & 200,0 & 200,0 \\
\hline $\mathbf{K}$ & 212,5 & 212,5 & 212,5 & 212,5 & 212,5 \\
\hline $\mathrm{Mg}$ & 40,5 & 40,5 & 40,5 & 40,5 & 40,5 \\
\hline $\mathbf{P}$ & 8,0 & 8,0 & 8,0 & 8,0 & 8,0 \\
\hline $\mathbf{S}$ & 83,2 & 83,2 & 83,2 & 68,3 & 68,3 \\
\hline $\mathrm{Cl}$ & 416,0 & 356,4 & 237,6 & 151,8 & 33,0 \\
\hline $\mathrm{Fe}$ & 4,85 & 4,85 & 4,85 & 4,85 & $4,85^{\circ}$ \\
\hline $\mathrm{Mn}$ & 0,67 & 0,67 & 0,67 & 0,67 & 0,67 \\
\hline B & 0,40 & 0,40 & 0,40 & 0,40 & 0,40 \\
\hline $\mathrm{Zn}$ & 0,17 & 0,17 & 0,17 & 0,17 & 0,17 \\
\hline $\mathrm{Cu}$ & 0,05 & 0,05 & 0,05 & 0,05 & 0,05 \\
\hline Mo & 0,11 & 0,11 & 0,11 & 0,11 & 0,11 \\
\hline
\end{tabular}

$\left.{ }^{1}{ }^{1}\right) \mathrm{O} \mathrm{Fe}$ foi adicionado na forma de Fe-EDTA; preparado com $\mathrm{FeSO}_{4} .7 \mathrm{H}_{2} \mathrm{O}$ e Na-EDTA; os demais nutrientes foram adicionados na forme dos sais: $\mathrm{Ca}\left(\mathrm{NO}_{3}\right)_{2} .4 \mathrm{H}_{2} \mathrm{O}, \mathrm{KNO}_{3}$, $\mathrm{K}_{2} \mathrm{SO}_{4}, \mathrm{KCl}, \mathrm{NH}_{4} \mathrm{NO}_{3}, \mathrm{MgSO}_{4} .7 \mathrm{H}_{2} \mathrm{O}, \mathrm{MnCl}_{2} .4 \mathrm{H}_{2} \mathrm{O}, \mathrm{H}_{3} \mathrm{BO}_{3}, \mathrm{ZnSO}_{4} .7 \mathrm{H}_{2} \mathrm{O}, \mathrm{CuSO}_{4} .5 \mathrm{H}_{2} \mathrm{O}$ e $\left(\mathrm{NH}_{4}\right)_{6} \mathrm{MO}_{7} \mathrm{O}_{24} \cdot 4 \mathrm{H}_{2} \mathrm{O}$.

A solução foi continuamente arejada, durante o decorrer do experimento, não sendo renovada, e, o volume dos vasos, completado diariamente com agua destilada.

O experimento consistiu em blocos casualizados com quatro repetições, totalizando 100 vasos, com uma planta por vaso. As médias das temperaturas máx imas e mínimas na casa de vegetação, durante o período de crescimento das plantas, foram $35 \pm 5$ e $23 \pm 5^{\circ} \mathrm{C}$ respectivamente. 
As plantas foram colhidas aos 30 dias de idade ( 23 dias em solução nutritiva), quando foi anotado o número de folhas e avaliado o grau de deficiência de nitrogênio pelos sintomas visuais apresentados A seguir, as plantas foram lavadas com água destilada e separadas em folhas, caules mais bainhas e raízes, sendo as partes assim separadas secas em estufa a $70^{\circ} \mathrm{C}$, pesadas e mordas As amostras foram então digeridas com ácido sulfúrico (em presença de catalisadores) e submetidas à análise química do $\mathrm{N}$, pelo método colorimétrico do indofenol, utilizando um auto-analisador II Technicon, de acordo com o procedimento descrito por BATAGLIA et alii (1983).

2. Seleção de trinta e nove linhagens de milho, quanto ao crescimento, absorção e utilização do $\mathrm{N}$, em solução nutritiva

O ensaio foi conduzido em casa de vegetação, no período de janeiro-fevereiro de 1983, no Centro Experimental de Campinas.

Utilizou-se o mesmo sistema descrito no ensaio anterior. A composição da solução nutritiva utilizada correspondeu à do tratamento $3(120 \mathrm{mg} / \mathrm{li}$ tro de $\mathrm{N}$ ), descrita no quadro 1 .

O ensaio consistiu em blocos casualizados, com quatro repetições, totalizando 156 vasos, com duas plantas por vaso, os quais foram espaçados e redistribuídos ao acaso na casa de vegetação, quando as plantas estavam mais desenvolvidas As médias das temperaturas máximas e mínimas na casa de vegetação, durante o período de crescimento das plantas, foram $37 \pm 4$ e $19 \pm 4^{\circ} \mathrm{C}$ respectivamente.

As plantas foram colhidas aos 27 dias de idade ( 20 dias em solução nutritiva), lavadas com água destilada e separadas em folhas, caules + bainhas e raízes. Foram anotados e avaliados os sintomas visuais de deficiência de $\mathrm{N}$, por meio de graus ou notas, de acordo com a severidade dos sintomas das plantas Determinaram-se os pesos da matéria seca das partes, que foram moídas e submetidas à análise química de $\mathrm{N}$.

Os genótipos foram classificados, segundo o intervalo de confiança obtido para a média geral de matéria seca total, com $99,9 \%$ de probabilidade e 38 graus de liberdade, numa distribuição $t: \bar{x} \pm t(0,001 ; 38)$. $s(\bar{x})$.

\section{RESULTADOS E DISCUSSÃo}

1. Ensaio com cinco linhagens de milho, em solução nutritiva, com diferentes niveis de $\mathbf{N}$

Os resultados obtidos encontram-se nos quadros 2 e 3 e nas figuras 1 e 2 . Observou-se resposta no crescimento das plantas até o nível de $120 \mathrm{mg} /$ litro de $\mathrm{N}$ para todas as linhagens Acima desse nível, as linhagens 
11.19.3.3(B) e 11.21.1.1(D), continuaram a se desenvolver, e as linhagens IA 2876.3.1.23(A) e 10.11.1.1(C) tiveram seus crescimentos reduzidos (Quadro 2, Figuras 1 e 2). Maior variabilidade entre linhagens, na produção de matéria seca, foi observada para os níveis de 60 e $120 \mathrm{mg} /$ litro de N (CV entre 16 e 17\%). Nos demais níveis de $\mathrm{N}$, a variabilidade entre linhagens diminuiu, principalmente com relação ao desenvolvimento da parte aérea (CV entre 3,7 e 11,9\%). Os teores de $\mathrm{N}$ atingiram valores máximos nas folhas, seguidos daqueles nos caules + bainhas, e, por último, nas raízes. De modo geral, os teores de $\mathrm{N}$ nas partes das plantas tenderam a aumentar com

QUADRO 2 - Matéria seca produzida por cinco linhagens de milho cultivadas até aos trinta dias de idade, em solução nutritiva com níveis de nitrogênio (uma planta/vaso de 2,8 litros, quatro repetiçð̃es)

\begin{tabular}{|c|c|c|c|c|c|}
\hline \multirow[b]{2}{*}{ Niveis de $\mathrm{N}$} & \multicolumn{5}{|c|}{ Linhagens $\left({ }^{1}\right)$} \\
\hline & A & B & $\mathrm{C}$ & $\mathrm{D}$ & $\mathrm{E}$ \\
\hline \multirow[t]{2}{*}{$\dot{\mathrm{m} g} / \mathrm{litro}$} & & 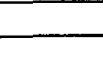 & g/planta & (2) & - \\
\hline & \multicolumn{5}{|c|}{ Matéria seca da parte aérea $\left({ }^{2}\right)$} \\
\hline 30 & 6,96 & 6,50 & 6,89 & 7,42 & 7,05 \\
\hline 60 & 10,83 & 8,28 & 11,55 & 9,41 & 12,51 \\
\hline 120 & 12,28 & 10,16 & 14,76 & 10,52 & 14,33 \\
\hline 180 & 12,49 & 10,48 & 12,51 & 11,30 & 12,22 \\
\hline \multirow[t]{2}{*}{240} & 11,65 & 11,52 & 12,34 & 11,53 & 14,84 \\
\hline & \multicolumn{5}{|c|}{ Matéria seca de raízes $\left({ }^{2}\right)$} \\
\hline 30 & 1,70 & 1,63 & 1,87 & 1,54 & 1,67 \\
\hline 60 & 2,18 & 1,61 & 2,49 & 1,77 & 2,53 \\
\hline 120 & 3,20 & 1,90 & 3,04 & 2,78 & 3,11 \\
\hline 180 & 2,91 & 2,26 & 3,48 & 3,47 & 2,59 \\
\hline \multirow[t]{2}{*}{240} & 2,63 & 2,64 & 2,84 & 3,40 & 3,84 \\
\hline & \multicolumn{5}{|c|}{ Matéria seca total $\left({ }^{2}\right)$} \\
\hline 30 & 8,67 & 8,10 & 8,76 & 8,96 & 8,72 \\
\hline 60 & 13,02 & 9,89 & 14,05 & 11,18 & 15,04 \\
\hline 120 & 15,48 & 12,06 & 17,81 & 13,32 & 17,45 \\
\hline 180 & 15,40 & 12,74 & 15,99 & 14,77 & 14,81 \\
\hline 240 & 14,28 & 14,16 & 15,18 & 14,93 & 18,68 \\
\hline
\end{tabular}

(1) $\mathrm{A}=\mathrm{IA} 2876.3 .1 .2 .3 ; \mathrm{B}=11.19 .3 .3 ; \mathrm{C}=10.11 .1 .1 ; \mathrm{D}=11.21 .1 .1 ; \mathrm{E}=11.1 .3 .1$.

$\left.{ }^{2}\right)$ Teste $F(0,01)$ significativo para linhagens e níveis de $N$. Interação níveis $x$ linhagens não significativa. 
os níveis crescentes de $\mathrm{N}$ na solução nutritiva, sendo que seus acréscimos foram mais acentuados do primeiro $(30 \mathrm{mg} / \mathrm{litro})$ para o segundo (60 $\mathrm{mg} / \mathrm{li}$ tro) e do segundo para o terceiro (120mg/litro) niveis de $\mathrm{N}$, como sè vê no quadro 3 , onde constam também os graus de deficiência de $\mathrm{N}$, avaliados mediante sintomas visuais exibidos pelas plantas

QUADRO 3 - Teores de nitrogênio (N) na matéria seca e grau de deficiência de $\mathrm{N}$ nas plantas de cinco linhagens de milho, cultivadas até os trinta dias de idade em solução nutritiva, com niveis de $\mathrm{N}$ (uma planta/vaso de 2,8 litros, quatro repetições)

\begin{tabular}{|c|c|c|c|c|c|}
\hline \multirow{2}{*}{ Níveis de $\mathrm{N}$} & \multicolumn{5}{|c|}{ Linhagens $\left({ }^{1}\right)$} \\
\hline & A & B & $\mathrm{C}$ & $\mathrm{D}$ & $\mathrm{E}$ \\
\hline $\mathrm{mg} /$ /itro & \multicolumn{5}{|c|}{ Nem follhas $(\%)\left({ }^{2}\right)$} \\
\hline 30 & 1,26 & 1,31 & 1,26 & 1,17 & 1,12 \\
\hline 60 & 1,76 & 2,27 & 1,45 & 1,71 & 1,32 \\
\hline 120 & 2,82 & 2,84 & 2,87 & 2,81 & 3,16 \\
\hline 180 & 3,03 & 3,61 & 3,58 & 2,94 & 2,98 \\
\hline \multirow[t]{2}{*}{240} & 2,85 & 3,19 & 2,76 & 2,93 & 3,34 \\
\hline & \multicolumn{5}{|c|}{$\mathrm{N}$ em caules e bainhas $(\%)\left({ }^{2}\right)$} \\
\hline 30 & 0,77 & 1,00 & 1,46 & 0,99 & 0,86 \\
\hline 60 & 1,18 & 1,66 & 1,27 & 1,06 & 1,05 \\
\hline 120 & 2,20 & 2,49 & 2,01 & 2,31 & 2,25 \\
\hline 180 & 2,66 & 2,66 & 2,54 & 2,12 & 2,22 \\
\hline \multirow[t]{2}{*}{240} & 2,90 & 3,06 & 2,51 & 2,35 & 2,42 \\
\hline & \multicolumn{5}{|c|}{$\mathrm{N}$ em raízes $(\%)\left({ }^{2}\right)$} \\
\hline 30 & 0,87 & 0,96 & 0,87 & 0,95 & 0,82 \\
\hline 60 & 1,18 & 1,49 & 0,95 & 1,36 & 1,06 \\
\hline 120 & 1,59 & 2,02 & 1,45 & 1,99 & 1,60 \\
\hline 180 & 2,40 & 2,46 & 2,54 & 2,16 & 2,40 \\
\hline \multirow[t]{2}{*}{240} & 2,58 & 2,84 & 2,69 & 2,73 & 1,96 \\
\hline & \multicolumn{5}{|c|}{ Grau de deficiência de $N\left({ }^{3}\right)$} \\
\hline 30 & 3,4 & 2,9 & 3,4 & 3,1 & 3,4 \\
\hline 60 & 2,5 & 2,6 & 2,4 & 1,9 & 2,6 \\
\hline 120 & 1,5 & 1,5 & 2,3 & 1,1 & 2,0 \\
\hline 180 & 1,8 & $1 ; 3$ & 1,3 & 1,4 & 1,4 \\
\hline 240 & 1,3 & 1,4 & 1,8 & 1,8 & 1,3 \\
\hline
\end{tabular}

( $\left.{ }^{1}\right) \mathrm{A}=$ IA 2876.3.1.2.3; $\mathrm{B}=11.19 .3 .3 ; \mathrm{C}=10.11 .1 .1 ; \mathrm{D}=11.21 .1 .1 ; \mathrm{E}=11.1 .3 .1$.

$\left({ }^{2}\right)$ Teste $F(0,01)$ significativo para linhagens e níveis de $\mathrm{N}$. Interação níveis $\mathrm{x}$ linhagens não significativa.

( $\left.{ }^{3}\right) 0=$ nenhuma; $4=$ severa. 


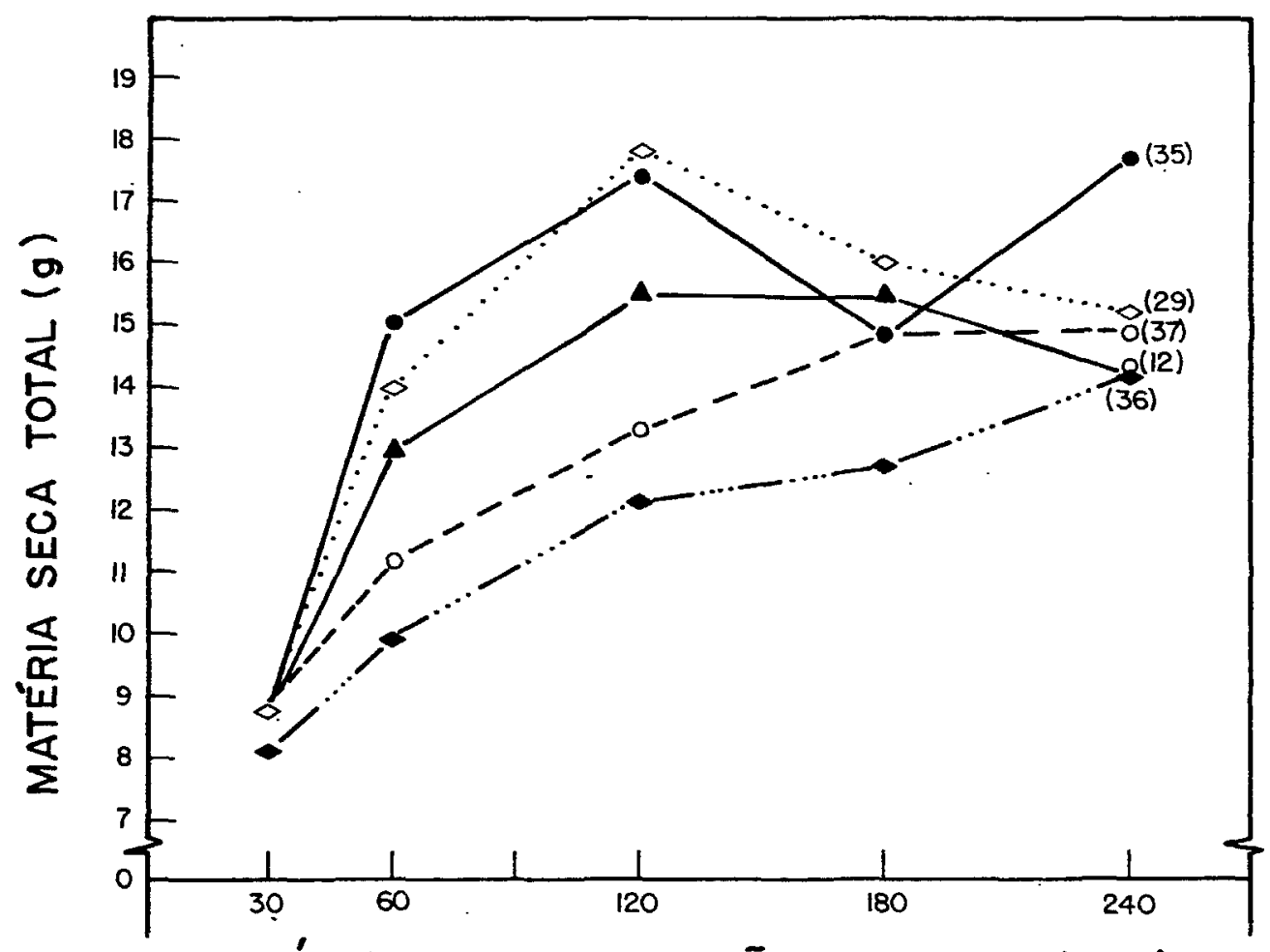

NÍVEIS DE N NA SOLUÇÃO NUTRITIVA (pp m)

FIGURA 1 - Matéria seca total produzida por linhagens de milho cultivadas até aos trinta dias de idade, em solução nutritiva com nf́veis de nitrogênio (médias de quatro repetiçбes).

O objetivo deste experimento foi definir, na solução nutritiva, um nível de $\mathrm{N}$ adequado para diferenciação das linhagens, quanto à eficiència na absorção e sua utilização nos niveis mais baixos, a fim de selecionar materiais genéticos menos exigentes e/ou com maiores capacidades de absorção, metabolização e emprego do nutriente para o crescimento. Pelos resultados obtidos neste ensaio, os niveis entre 60 e $120 \mathrm{mg} /$ litro de $\mathrm{N}$ mostraram-se mais adequados ao objetivo proposto, pois, abaixo deles, as plantas se mostraram severamente deficientes e as linhagens não puderam ser diferenciadas pelos pesos de matéria seca total; acima desses níveis, algumas linhagens apresentaram crescimen to reduzido. 


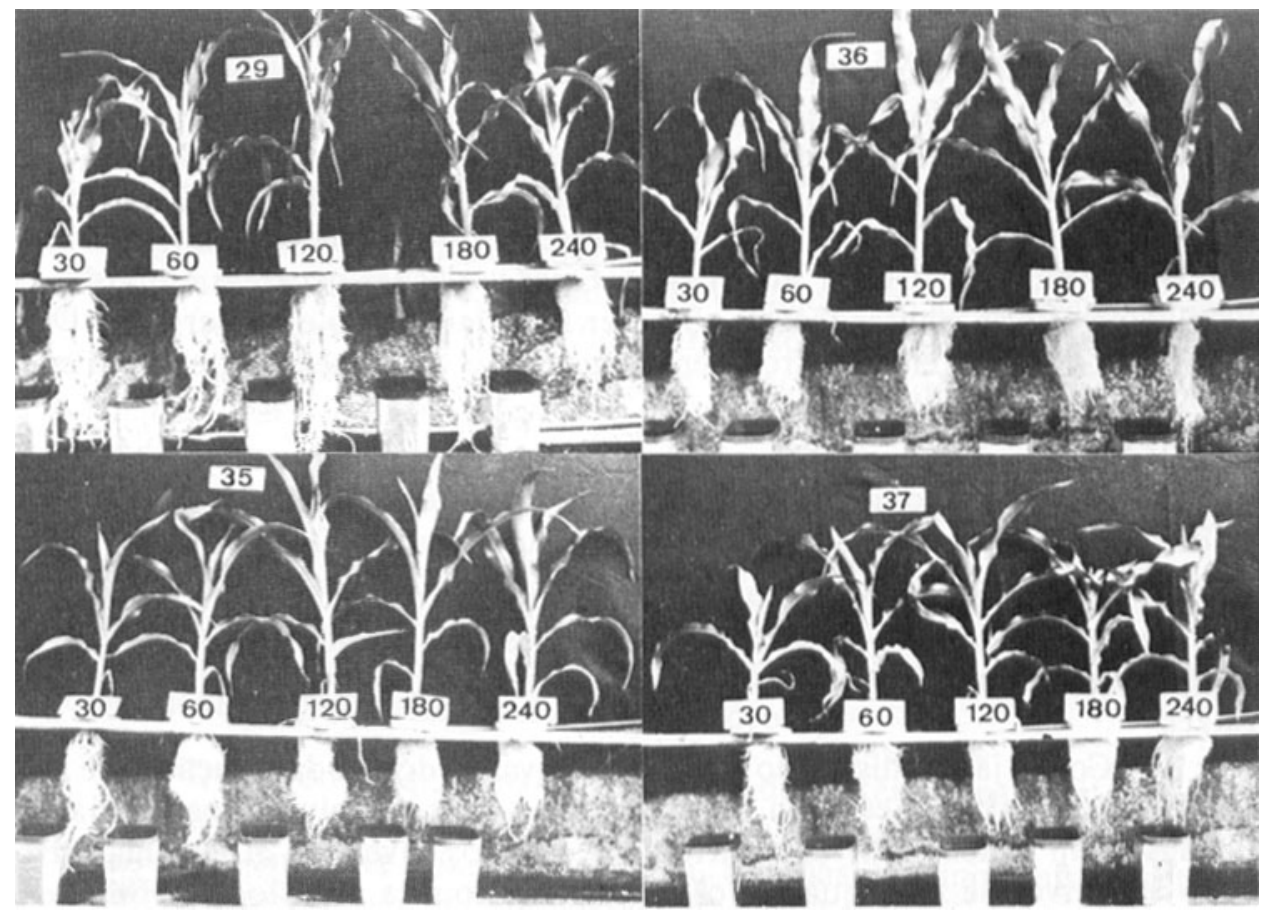

FIGURA 2 - Aspecto de quatro linhagens de milho cultivadas até aos trinta dias de idade, em solução nutritiva com níveis de nitrogênio (médias de quatro repetiçðes).

Foi adotado, então, o nível de $120 \mathrm{mg} /$ litro de $\mathrm{N}$ para o experimento subseqüente, no qual foram testadas trinta e nove linhagens, no mesmo sistema, utilizando-se duas plantas por vaso.

$\mathrm{Na}$ figura 3, estão registradas as variações de $\mathrm{pH}$ para a linhagem 11.01.3. 1(E) cultivada com diferentes níveis de $\mathrm{N}$ na solução nutritiva, antes de serem feitas as correções ou reajustes. Observou-se que no nível mais baixo de $\mathrm{N}$, o pH começou a se elevar acima de 6,0 após o 80 dia de crescimento das plantas em soluçấo, e, à medida que o nível de $\mathrm{N}$ foi aumentando, mais tempo demorou para ocorrer tal elevação. No nível de $240 \mathrm{mg} / \mathrm{litro}$, o $\mathrm{pH}$ começou a elevar-se somente após o 15 o dia de crescimento das plantas em solução (para algumas linhagens, não chegou a ultrapassar 6,0 até o dia da colheita).

Isso ocorreu devido à presença de quantidades crescentes de $\mathrm{NH}_{4}^{+}$na soluçãa $\mathrm{Em}$ todos os níveis de $\mathrm{N}$, foi mantida a proporção $\mathrm{NO}_{3}^{-} / \mathrm{NH}_{4}^{+}=8$ (Quadro 1). Já é sabido que fontes de $\mathrm{N}$ influenciam a direção que o $\mathrm{pH}$ toma 
(BERNARDO et alii, 1982; CLARK, 1982; CLARK \& BROWN, 1974; FLEMING, 1983); ele aumenta para cerca de 7,0 ou 8,0 em soluções contendo apenas $\mathrm{NO}_{3}^{-}$como fonte de $\mathrm{N}$, e diminui para cerca de 4,0 em soluções contendo algum $\mathrm{NH}_{4}^{+}$. Entretanto, o $\mathrm{pH}$ aumentará se a proporção de $\mathrm{NH}_{4}^{+}$em relação ao $\mathrm{NO}_{3}^{-}$for muito baix a (BERNARDO et alii, 1982; CLARK, 1982; FLEMING, 1983), ou quando o $\mathrm{NH}_{4}^{+}$desaparece da solução, deixando apenas $\mathrm{NO}_{3}^{-}$(BERNARDO et alii, 1982). Essas variações ocorrem em vista da habilidade que as plantas têm de absorver ions da solução e liberar $\mathrm{H}^{+} \mathrm{e} \mathrm{OH}^{-}$ ou $\mathrm{HCO}_{3}^{-}$, num sistema de troca em resposta ao crescimento e metabolismo (HIAT \& LEGGETT, 1974).

Para evitar problemas de deficiências nutricionais nas plantas, pela elevação do $\mathrm{pH}$ na solução nutritiva, seus valores foram medidos em cada vaso de dois em dois dias e reajustados com soluçăo de $\mathrm{H}_{2} \mathrm{SO}_{4} 0,1 \mathrm{~N}$.

A necessidade de reajuste do $\mathrm{pH}$ variou com o nível de $\mathrm{N}$ na solução e com a linhagem, evidenciando variações na capacidade das plantas em alterar o pH das soluções, em conseqüência da diferente atividade de suas raízes

Como já foi discutido, a fase de elevação do $\mathrm{pH}$ da solução teve início quando o $\mathrm{NH}_{4}^{+}$se esgotou, ficando apenas $\mathrm{NO}_{3}^{-}$na solução, para todas as linhagens em todos os níveis. Entretanto, para os níveis de 30 e $60 \mathrm{mg} /$ litro de $\mathrm{N}$, observou-se que, quando o $\mathrm{NO}_{3}^{-}$se esgotou da solução, o pH decresceu para valores ao redor de 4,0, onde permaneceu ate final do experimento, dispensando reajustes, visto que, nessa faixa de $\mathrm{pH}$, não havia danos às plantas (FURLANI et alii, 1985). Nos níveis mais elevados $(120,180 \mathrm{e}$ $240 \mathrm{mg} /$ litro de $\mathrm{N}$ ), isso não ocorreu, pois o $\mathrm{NO}_{3}^{-}$não foi completamente esgotado na solução.

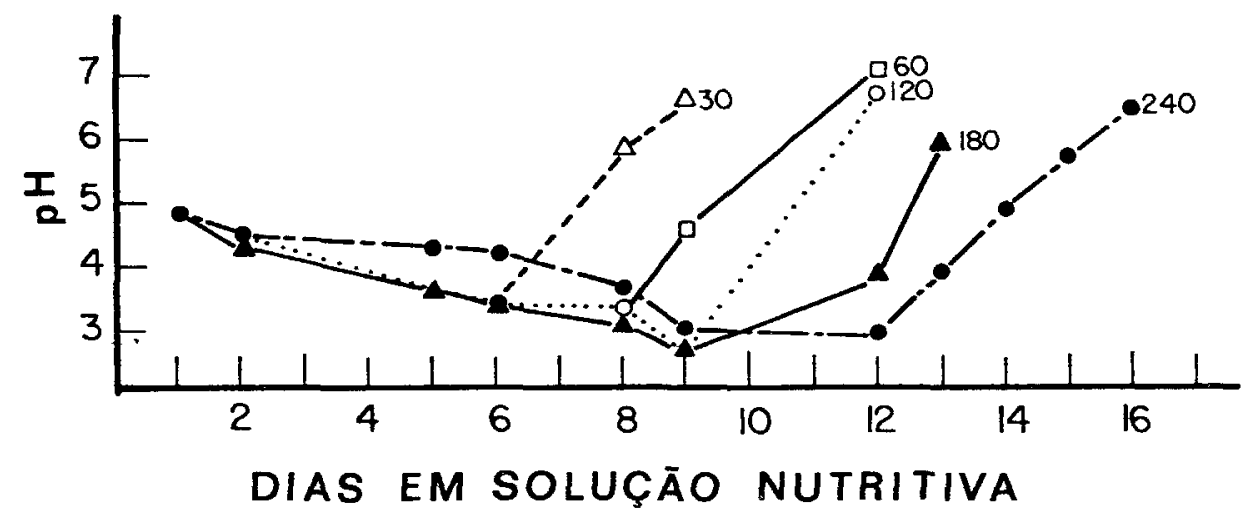

FIGURA 3 - Variação do $\mathrm{pH}$ da solução nutritiva com o crescimento das plantas da linhagem 11.01.3.1, em função dos níveis de nitrogênio: $30,60,120,180$ e $240 \mathrm{mg} /$ litro de $\mathrm{N}$ (médias de quatro repetiçðes). 
2. Seleção de trinta e nove linhagens, quanto à absorção e utilização de $\mathbf{N}$, em solução nutritiva

No quadro 4, são apresentados os dados de produção de matéria seca de 39 linhagens cultivadas durante 20 dias em solução nutritiva com $120 \mathrm{mg} /$ litro de $\mathrm{N}$. Os dados foram colocados em ordem crescente de produção de matéria seca total $\mathrm{A}$ análise de variância revelou diferenças significativas entre os genótipos $(\alpha=0,01)$ para peso seco de parte aérea, de raízes e da planta inteira, com amplitudes de variação de 5,09 a 11,58, 0,88 a 2,97 e 6,20 a 14,32 respectivamente. Foi observada maior variabilidade no peso seco de raízes, expressa pelo coeficiente de variação das médias $(28,5 \%)$. $\mathrm{Na}$ figura 4, pode-se observar o aspecto de algumas linhagens no momento da colheita.

As linhagens cujas médias de matéria seca total se enquadraram abaixo do intervalo de confiança $(8,64 \mathrm{a} 11,10 \mathrm{~g})$, foram classificadas como ineficientes (I), acima do in tervalo como eficientes (E) e dentro do intervalo como medianamente eficientes (ME) (Quadro 4).

De modo geral, a maior produção de matéria seca total pelas plantas das linhagens eficientes foi conseqüência do maior crescimento tanto da parte aérea como das raízes. Entretanto, algumas das linhagens classificadas como eficientes se salientaram pelo melhor desenvolvimento do sistema radicular, apresentando menor relação parte aérea/raízes, como as de número 2 , 25,32 e 42

Dentre as medianamente eficientes, as de números $28,41,3$ e 24 também mostraram sistemas radiculares bem desenvolvidos (Quadro 4)

No estudo envolvendo seleção de linhagens de milho em baixo nivel de P (FURLANI et alii, 1985), sua classificação não seguiu a mesma ordem, mas as de números $42,25,43$ e 41, classificadas como eficientes em baixo $P$, salientaram-se também pelo desenvolvimento radicular, e as de números $34-\mathrm{L}$ $42,25,43$ e 39 foram classificadas como eficientes tanto para baixo $\mathrm{P}$ como para baixo $\mathrm{N}$.

No quadro 5, estão relacionados os teores de $\mathbf{N}$ nas partes das plantas, seguindo-se a mesma ordem de colocação dos dados de matéria seca total. Os teores de $\mathrm{N}$ foram mais elevados nas partes das plantas que se desenvolveram menos, decrescendo gradativamente nas que se desenvolveram mais (coeficientes de correlação, $r$, negativos), evidenciando um efeito de diluição ocorrido com o maior crescimento das plantas.

A partir dos teores de $\mathrm{N}$ e dos pesos de matéria seca das partes das plantas, foram calculados os conteúdos de $\mathrm{N}$ nas plantas inteiras de cada linhagem, a relação parte aérea/raízes desse conteúdo e a relação de eficiência (matéria seca produzida por unidade de $\mathrm{N}$ absorvida) (Quadro 6). 
QUADRO 4 - Matéria seca produzida por trinta e nove linhagens de milho cultivadas até aos vinte e sete dias de idade em solução nutritiva com $120 \mathrm{mg} /$ litro de $\mathrm{N}$ (duas plantas por vaso de 2,8 litros, quatro repetiçסes)

\begin{tabular}{|c|c|c|c|c|c|}
\hline & Linhagem & & atéria seca & & Classifi- \\
\hline N! & Código & Parte aérea & Raízes & Total & caçăo( $\left.{ }^{1}\right)$ \\
\hline & & & $\mathrm{g} /$ duas $\mathrm{p}$ & lantas - & \\
\hline 04 & Ip 48.5 .3 & 5,09 & 1,11 & 6,20 & I \\
\hline 26 & 745 & 5,59 & 1,03 & 6,61 & I \\
\hline 01 & Porto Rico 70.D.2 & 5,46 & 1,20 & 6,65 & I \\
\hline 40 & 11.23 .3 .1 & 5,44 & 1,35 & 6,80 & I \\
\hline 27 & 820 & 6,07 & 0,88 & 6,95 & I \\
\hline 05 & Ip 365.4 .1 & 5,67 & 1,36 & 7,03 & I \\
\hline 13 & IA. 2992.1 .1 .2 .3 & 6,06 & 1,44 & 7,50 & I \\
\hline 15 & T. $8 \times$ Asteca 10.10 .1 .2 .12 & 6,17 & 1,53 & 7,68 & I \\
\hline 18 & 490 & 6,13 & 1,87 & 8,00 & I \\
\hline 37 & 11.21 .1 .1 & 6,49 & 1,56 & 8,05 & I \\
\hline 11 & $\operatorname{Pm} 624.2 .1$ & 6,42 & 1,68 & 8,10 & I \\
\hline 30 & 10.13 .1 .1 & 6,91 & 1,43 & 8,33 & I \\
\hline 23 & 532 & 6,74 & 1,63 & 8,37 & I \\
\hline 36 & 11.19 .3 .3 & 7,34 & 1,37 & 8,71 & $\mathrm{ME}$ \\
\hline 06 & Ip 837.1.1.1 & 7,15 & 1,61 & 8,76 & $\mathrm{ME}$ \\
\hline 10 & Ip 421.2.1.1 & 7,29 & 1,80 & 9,10 & $\mathrm{ME}$ \\
\hline 07 & Ip 321 & 7,35 & 1,91 & 9,26 & $\mathrm{ME}$ \\
\hline 24 & 535.2 & 7,34 & 2,41 & 9,75 & $\mathrm{ME}$ \\
\hline 31 & 10.19 .1 .1 & 7,85 & 2,10 & 9,94 & $\mathrm{ME}$ \\
\hline 12 & IA 2876.3 .1 .2 .3 & 8,38 & 1,71 & 10,08 & $\mathrm{ME}$ \\
\hline 03 & Ip 701.1 .1 & 7,85 & 2,29 & 10,15 & $\mathrm{ME}$ \\
\hline 34-A & 10.40 .1 & 8,25 & 2,05 & 10,30 & $\mathrm{ME}$ \\
\hline 44 & 723.4 & 8,19 & 2,17 & 10,39 & ME \\
\hline 33 & 10.36 .1 & 8,89 & 1,65 & 10,53 & ME \\
\hline 41 & 11.24.1.1 & 8,45 & 2,53 & 10,98 & ME \\
\hline 28 & 10.8.2.1 & 8,44 & 2,65 & 11,08 & $\mathrm{ME}$ \\
\hline 02 & SLP 103.3.2 & 8,78 & 2,57 & 11,35 & $\mathrm{E}$ \\
\hline 20 & 519 & 9,32 & 2,19 & 11,51 & $\mathrm{E}$ \\
\hline 21 & 137 & 9,39 & 2,44 & 11,83 & $\mathbf{E}$ \\
\hline 16 & V 2017 Cuban Dent. & 9,67 & $\overrightarrow{2}, 21$ & 11,88 & $\mathrm{E}$ \\
\hline 25 & 641.2 & 8,93 & 2,97 & 11,89 & $\mathbf{E}$ \\
\hline 39 & 11.22 .2 .3 & 9,87 & 2,03 & 11,90 & $\mathbf{E}$ \\
\hline 32 & 10.20 .3 .1 & 9,04 & 2,90 & 11,94 & $\bar{E}$ \\
\hline $4 \overline{3}$ & 124.3 .15 .1 & 9,53 & 2,47 & 11,99 & $\overline{\mathrm{E}}$ \\
\hline 42 & 11.30 .1 .1 & 9,42 & 2,73 & 12,14 & $\overline{\mathbf{E}}$ \\
\hline 29 & 10.11 .1 .1 & 9,92 & 2,59 & 12,51 & $\bar{E}$ \\
\hline 35 & 11.01 .3 .1 & 1059 & 232 & 1291 & $\mathrm{E}$ \\
\hline 34-L & 10.40 .1 & 10,92 & 2,69 & 13,60 & $\mathbf{E}$ \\
\hline 22 & 531 & 11,58 & 2,73 & 14,32 & $\mathbf{E}$ \\
\hline $\mathrm{CV}$ d & nédias \% & 21,2 & 28,5 & 21,7 & \\
\hline Ampl & de de variação & $5,09-11,58$ & $0,88-2,97$ & $6,20-14,32$ & \\
\hline Inter & de confiança $\left({ }^{2}\right)$ & & & $9,87 \pm 1,23$ & \\
\hline
\end{tabular}

$\left({ }^{1}\right) \mathrm{I}=$ ineficiente; $\mathrm{ME}=$ medianamente eficiente; $\mathrm{E}=$ eficiente.

( ${ }^{2}$ Intervalo de confiança para a média, calculado com $99,9 \%$ de probabilidade, numa distribuição t: $\overline{\bar{x}} \pm t(0,001 ; 38) \cdot s(\bar{x})$. 

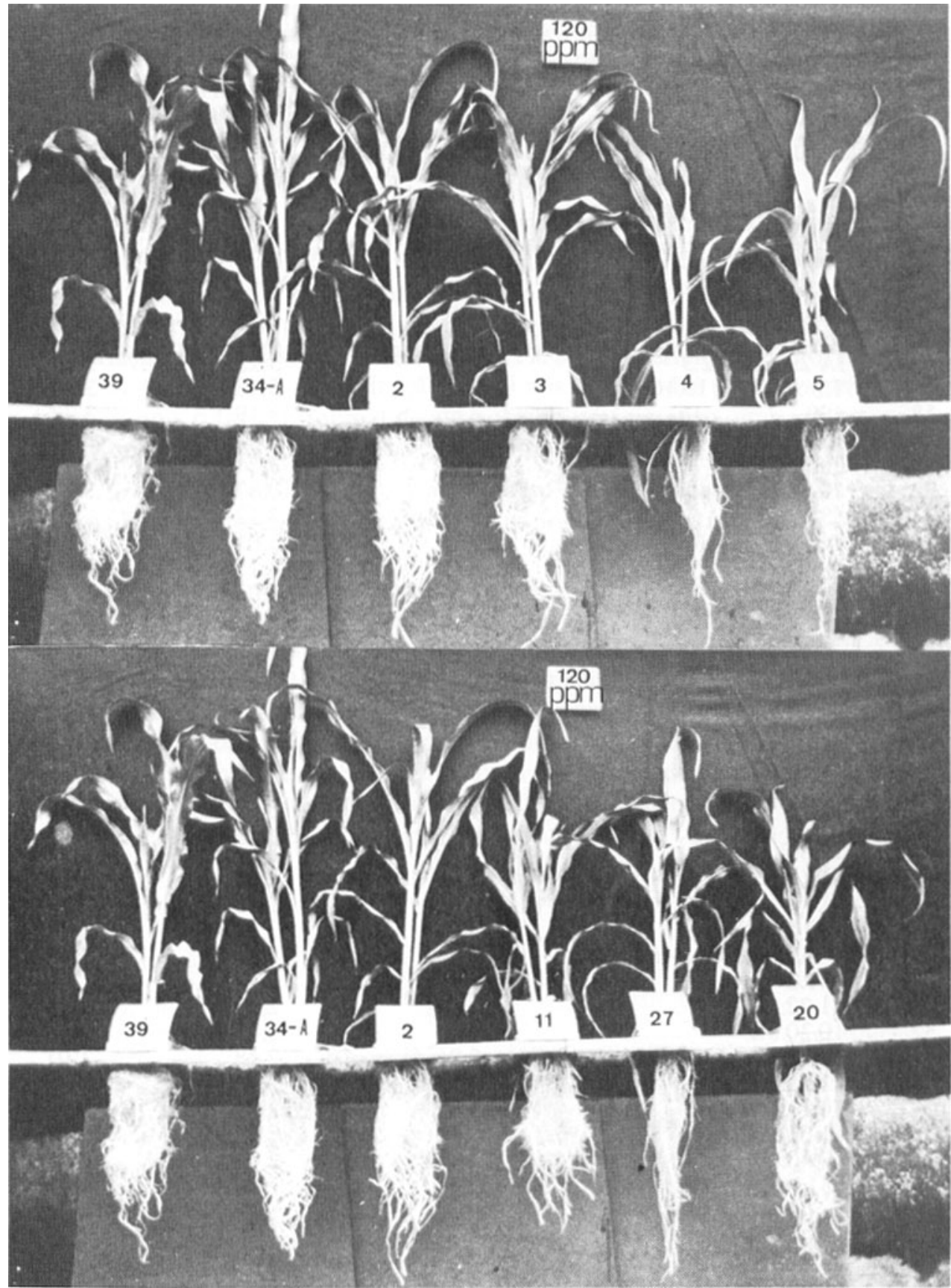

FIGURA 4 - Aspecto das linhagens de milho aos vinte e sete dias de idade, selecionadas em solução nutritiva com $120 \mathrm{mg} /$ litro de N: $39,34-\mathrm{A}, 2,3,4,5,11,27$ e 20). 
QUADRO 5 - Teores de nitrogênio na matéria seca de plantas de trinta e nove linhagens de milho cultivadas até aos vinte e sete dias de idade, em solução nutritiva com $120 \mathrm{mg} /$ litro de $\mathrm{N}$ (duas plantas por vaso de 2,8 litros, quatro repetiçøes)

\begin{tabular}{|c|c|c|c|c|}
\hline \multicolumn{2}{|c|}{ Linhagem } & \multicolumn{3}{|c|}{ Nitrogênio ( $\left.{ }^{1}\right)$} \\
\hline No & Código & Folhas & Caules + Bainhas & Raízes \\
\hline 04 & In 48.5 .3 & 4,40 & $=\%$ & 3.82 \\
\hline 26 & 745 & 4,40 & 3,95 & 3,29 \\
\hline 01 & Porto Rico 70.D.2 & 4,15 & 3,39 & 3,68 \\
\hline 40 & 11.23 .3 .1 & 4,05 & 3,51 & 3,12 \\
\hline 27 & 820 & 4,13 & 3,44 & 4,25 \\
\hline 05 & Ip 365.4.1 & 4,27 & 3,42 & 3,39 \\
\hline 13 & IA 2992.1.1.2.3 & 4,21 & 3,25 & 3,77 \\
\hline 15 & T. $8 \times$ Asteca 10.10 .1 .2 .12 & 4,02 & 3,48 & 3,50 \\
\hline 18 & 490 & 3,86 & 3,19 & 3,33 \\
\hline 37 & 11.21.1.1 & 3,27 & 2,54 & 3,32 \\
\hline 11 & $\operatorname{Pm} 624.2 .1$ & 3,75 & 3,24 & 3,64 \\
\hline 30 & 10.13.1.1 & 3,21 & 2,87 & 3,49 \\
\hline 23 & 532 & 3,98 & 3,12 & 2,87 \\
\hline 36 & 11.19.3.3 & 3,34 & 3,01 & 3,64 \\
\hline 06 & Ip 837.1.1.1 & 3,70 & 3,15 & 3,33 \\
\hline 10 & Ip 421.2 .1 .1 & 3,51 & 3,05 & 2,35 \\
\hline 07 & Ip 321 & 3,62 & 2,79 & 2,38 \\
\hline 24 & 535.2 & 3,44 & 2,45 & 2,79 \\
\hline 31 & 10.19.1.1 & 3,60 & 2,48 & 2,65 \\
\hline 12 & IA 2876.3 .1 .2 .3 & 3,74 & 2,76 & 2,46 \\
\hline 03 & Ip 701.1.1 & 3,28 & 2,76 & 2,46 \\
\hline 34-A & 10.40 .1 & 3,36 & 2,59 & 2,48 \\
\hline 44 & 723.4 & 3,12 & 2,73 & 1,75 \\
\hline 33 & 10.36 .1 & 4,34 & 2,89 & 2,50 \\
\hline 41 & 11.24.1.1 & 2,95 & 2,89 & 3,10 \\
\hline 28 & 10.8.2.1 & 3,12 & 2,81 & 2,14 \\
\hline 02 & SLP 103.3.2 & 3,47 & 2,48 & 2,15 \\
\hline 20 & 519 & 3,12 & 2,69 & 2,51 \\
\hline 21 & 137 & 3,00 & 2,54 & 2,05 \\
\hline 16 & V 2017 Cuban Dent. & 2,88 & 2,45 & 2,01 \\
\hline 25 & 641.2 & 3,40 & 2,27 & 2,00 \\
\hline 39 & 11.22.2.3 & 3,06 & 2,41 & 2,37 \\
\hline 32 & 10.20.3.1 & 3,07 & 2,47 & 2,51 \\
\hline 43 & 124.3.15.1 & 2,96 & 2,48 & 2,10 \\
\hline 42 & 11.30 .1 .1 & 2,98 & 2,19 & 2,05 \\
\hline 29 & 10.11 .1 .1 & 2,89 & 2,23 & 2,07 \\
\hline 35 & 11.01.3.1 & 2,95 & 2,22 & 1,92 \\
\hline 34-L & 10.40 .1 & 2,82 & 2,00 & 2,14 \\
\hline 22 & 531 & 2,98 & 2,05 & 1,76 \\
\hline CV d & médias \% & 14,2 & 16,9 & 24,8 \\
\hline Ampl & de de variação & $2,824,40$ & $2,00-3,95$ & $1,75-4,25$ \\
\hline Coefi & nte de correlação $\left({ }^{2}\right)$ & $-0,83$ & $-0,84$ & $-0,82$ \\
\hline
\end{tabular}

$\left({ }^{1}\right)$ Teste $F(0,01)$ significativo para diferenças entre linhagens.

(2) Coeficientes de correlação (r) entre pesos de matéria seca das partes das plantas e respectivos teores de $\mathbf{N}$. 
Embora os teores de $\mathrm{N}$ tenham tido uma relação inversa com a produção de matéria seca, os dados de seu conteúdo total variaram proporcionalmente com a matéria seca, apresentando um coeficiente de variação das médias de $8,7 \%$ e um coeficiente de correlação (r) de 0,87 . Essa variação no conteúdo total de $\mathrm{N}$ é uma indicação da existência de diferenças nas capacidades das plantas em absorvê-lo.

A distribuiçã்o de $\mathrm{N}$ na parte aérea e nas raízes não esteve relacionada com as variações observadas na matéria seca $(r=0,05)$ (Quadro 6).

Entretanto, os dados de relação de eficiência acompanharam a variação observada na produção de matéria seca, apresentando um coeficiente de variação das médias da ordem de $16,1 \%$ e um coeficiente de correlação (r) de 0,92 (Quadro 6). A utilização do $\mathrm{N}$ nos tecidos das plantas aparece, portanto, como o fator principal de variação no crescimento, embora o processo de absorção também tenha tido certa influência

No quadro 7, estão os valores de $\mathrm{pH}$ registrados durante os onze primeiros dias de crescimento das plantas na solução nutritiva, com $120 \mathrm{mg} /$ litro de N.

$\mathrm{O}$ pH se manteve baixo até o 80 dia de crescimento, como era esperado pelos dados obtidos no ensaio anterior. No 11 dia, elevou-se bruscamente para a maior parte das linhagens, e foi reajustado para cerca de 5,0-5,5 com solução de $\mathrm{H}_{2} \mathrm{SO}_{4} 0,1 \mathrm{~N}$, três vezes por semana, sendo os volumes gastos anotados até o final do experimento Observou-se que para determinadas linhagens, principalmente as que mais se desenvolveram, foi necessário maior volume de solução de $\mathrm{H}_{2} \mathrm{SO}_{4} 0,1 \mathrm{~N}$, para manter o $\mathrm{pH}$ ao redor de 5,0 As linhagens com menor crescimento apresentaram uma tendência de elevação de pH mais lenta, havendo menor gasto da solução ácida (Quadro 7). 
QUADRO 6 - Conteúdo total de $\mathrm{N}$, relação parte aérea/raízes do conteúdo de $\mathrm{N}$, relação de eficiência e grau de deficiência de $\mathbf{N}$, de trinta e nove linhagens de milho, cultivadas até aos vinte e sete dias de idade, em solução nutritiva com $120 \mathrm{mg} /$ litro de $\mathrm{N}$ (duas plantas/vaso de 2,8 litros, quatro repetiçбes)

\begin{tabular}{|c|c|c|c|c|c|}
\hline \multicolumn{2}{|r|}{ Linhagem } & \multicolumn{2}{|c|}{ Conteúdo de $\mathrm{N}$} & \multirow{2}{*}{$\begin{array}{l}\text { Relação de } \\
\text { eficiência }\end{array}$} & \multirow{2}{*}{$\begin{array}{c}\text { Grau de } \\
\text { deficiência }\left({ }^{1}\right)\end{array}$} \\
\hline \multirow[t]{2}{*}{ Nọ } & \multirow[t]{2}{*}{ Codigo } & Iotal & /raizes & & \\
\hline & & mg & $\mathrm{mg} / \mathrm{mg}$ & $\mathrm{mg} \mathrm{MS/mg} \mathrm{N}$ & \\
\hline 04 & Ip 48.5.3 & 247 & 5,0 & 25 & 1,2 \\
\hline 26 & 745 & 269 & 7,1 & 25 & 2,5 \\
\hline 01 & Porto Rico 70.D.2 & 253 & 4,7 & 26 & 2,0 \\
\hline 40 & 11.23 .3 .1 & 257 & 5,9 & 27 & 1,7 \\
\hline 27 & 820 & 264 & 6,3 & 26 & 3,0 \\
\hline 05 & Ip 365.4 .1 & 267 & 5,0 & 26 & 1,7 \\
\hline 13 & IA 2992.1.1.2.3 & 297 & 4,6 & 25 & 2,0 \\
\hline 15 & T.8 $\times$ Asteca 10.10.1.2.12 & 252 & 4,2 & 30 & 1,2 \\
\hline 18 & 490 & 284 & 3,5 & 28 & 2,5 \\
\hline 37 & 11.21 .1 .1 & 246 & 3,6 & 33 & 2,2 \\
\hline 11 & Pm 624.2.1 & 285 & 3,7 & 28 & 2,2 \\
\hline 30 & 10.13.1.1 & 260 & 4,3 & 32 & 2,0 \\
\hline 23 & 532 & 288 & 5,3 & 29 & 2,0 \\
\hline 36 & 11.19 .3 .3 & 304 & 5,2 & 29 & 2,5 \\
\hline 06 & Ip 837.1.1.1 & 290 & 5,0 & 30 & 3,0 \\
\hline 10 & Ip 421.2 .1 .1 & 285 & 5,9 & 32 & 1,7 \\
\hline 07 & Ip 321 & 294 & 5,5 & 32 & 1,7 \\
\hline 24 & 535.2 & 302 & 3,6 & 32 & 2,7 \\
\hline 31 & 10.19 .1 .1 & 299 & 4,4 & 33 & 3,5 \\
\hline 12 & IA 2876.3 .1 .2 .3 & 319 & 6,1 & 32 & 2,7 \\
\hline 03 & $\operatorname{lp} 701.1 .1$ & 290 & 4,3 & 44 & 2,2 \\
\hline 34-A & 10.40 .1 & 299 & 4,9 & 35 & 2,0 \\
\hline 44 & 723.4 & 281 & 4,8 & 37 & 2,7 \\
\hline 33 & 10.36 .1 & 310 & 6,4 & 34 & 3,0 \\
\hline 41 & 11.24 .1 .1 & 328 & 3,1 & 33 & 3,0 \\
\hline 28 & 10.8.2.1 & 308 & 4,5 & 36 & 2,2 \\
\hline 02 & SLP 103.3.2 & 319 & 4,8 & 36 & 2,2 \\
\hline 20 & 519 & 320 & 5,2 & 37 & 3,0 \\
\hline 21 & 137 & 314 & 5,3 & 38 & 3,7 \\
\hline 16 & V 2017 Cuban Dent. & 301 & 5,9 & 39 & 3,7 \\
\hline 25 & 641.2 & 314 & 4,0 & 38 & 3,0 \\
\hline 39 & 11.22 .2 .3 & 324 & 5,8 & 37 & 3,7 \\
\hline 32 & 10.20 .3 .1 & 324 & 3,7 & 37 & 2,2 \\
\hline 43 & 124.3.15.1 & 310 & 5,2 & 39 & 4,0 \\
\hline 42 & 11.30 .1 .1 & 303 & 4,6 & 40 & 3,0 \\
\hline 29 & 10.11.1.1 & 312 & 5,0 & 40 & 3,7 \\
\hline 35 & 11.01 .3 .1 & 322 & 6,3 & 40 & 3,7 \\
\hline 34-L & 10.40 .1 & 324 & 4,8 & 42 & 3,5 \\
\hline 22 & 531 & 348 & 6,4 & 41 & 3,7 \\
\hline \multicolumn{2}{|c|}{ CV das médias (\%) } & 8,7 & 18,6 & 16,1 & \\
\hline \multicolumn{2}{|c|}{ Amplitude de variaçăo } & $246-348$ & $3,1-7,1$ & $25-44$ & $1,2-4,0$ \\
\hline \multicolumn{2}{|c|}{ Coeficiente de correlaçðo $\left({ }^{2}\right)$} & 0,87 & 0,05 & 0,92 & \\
\hline
\end{tabular}

$\left({ }^{1}\right) 0=$ nenhuma; $4,0=$ severa. Número total de folhas variou de 10 a 14 .

$\left({ }^{2}\right)$ Coeficientes de correlação (r) entre pesos de matéria seca total e conteúdos de $\mathrm{N}$ e relação de eficiência. 
QUADRO 7 - Valores de $\mathrm{pH}$ registrados durante os onze primeiros dias de crescimento das linhagens em soluçaro nutritiva, e volume de $\mathrm{H}_{2} \mathrm{SO}_{4} \quad 0,1 \mathrm{~N}$ gasto durante os últimos nove dias, para correçăo do $\mathrm{pH}$ para 5,0-5,5 (médias de quatro repe tiçбes)

\begin{tabular}{|c|c|c|c|c|c|c|c|}
\hline & Linhagem & & Dias en & oluçã & tritiv & & $\begin{array}{l}\text { Volume de } \\
\mathrm{f}_{2} \mathrm{SO}_{4} \mathrm{O}, 1 \mathrm{~N}(1)\end{array}$ \\
\hline No & $\overline{\text { Código }}$ & 2 & 4 & 6 & 8 & 11 & \\
\hline & & & & $\mathrm{pH}\left({ }^{2}\right)$ & & & $\mathrm{ml}$ \\
\hline 04 & Ip 48.53 & 4,7 & 4,2 & 4,1 & 3,9 & 4,6 & 26 \\
\hline 26 & 745 & 4,8 & 4,4 & 4,5 & 4,6 & 7,1 & 38 \\
\hline 01 & Porto Rico 70.D. 2 & 4,8 & 4,2 & 4,1 & 4,2 & 5,4 & 23 \\
\hline 40 & 11.23 .3 .1 & 4,7 & 4,4 & 4,2 & 3,9 & 5,4 & 40 \\
\hline 27 & 820 & 4,8 & 4,4 & 4,2 & 4,0 & 5,0 & 29 \\
\hline 05 & Ip 365.4 .1 & 4,8 & 4,2 & 4,1 & 4,1 & 4,8 & 42 \\
\hline 13 & IA 2992.1 .1 .2 .3 & 4,8 & 4,2 & 4,1 & 4,1 & 7,0 & 26 \\
\hline 15 & T.8 X Asteca 10.10.1.2.12 & 4,8 & 4,6 & 4,6 & 4,5 & 5,3 & 43 . \\
\hline 18 & 490 & 4,7 & 4,1 & 4,1 & 4,1 & 7,0 & 28 \\
\hline 37 & 11.21 .1 .1 & 4,5 & 3,7 & 3,5 & 3,3 & 3,6 & 29 \\
\hline 11 & $\operatorname{Pm} 624.2 .1$ & 4,9 & 4,2 & 4,0 & 4,0 & 6,0 & 23 \\
\hline 30 & 10.13 .1 .1 & 4,7 & 4,5 & 4,4 & 4,2 & 7,0 & 42 \\
\hline 23 & 532 & 4,8 & 4,2 & 4,2 & 4,1 & 6,4 & 33 \\
\hline 36 & 11.19 .3 .3 & 4,8 & 4,2 & 4,0 & 3,9 & 6,8 & 28 \\
\hline 06 & ip 837.1.1.1 & 4,6 & 4,2 & 4,1 & 4,2 & 6,1 & 47 \\
\hline 10 & Ip 421.2 .1 .1 & 4,8 & 4,4 & 4,2 & 4,4 & 6,8 & 34 \\
\hline 07 & Ip 321 & 4,8 & 4,2 & 4,0 & 3,8 & 6,8 & 33 \\
\hline 24 & 535.2 & 4,7 & 4,4 & 4,2 & 4,3 & 6,6 & 39 \\
\hline 31 & 10.19 .1 .1 & 4,6 & 3,7 & 3,6 & 3,4 & 6,4 & 41 \\
\hline 12 & IA 2876.3 .1 .2 .3 & 4,7 & 4,0 & 3,9 & 3,7 & 7,1 & 33 \\
\hline 03 & Ip 701.1 .1 & 4,8 & 4,2 & 4,1 & 4,1 & 6,8 & 44 \\
\hline 34-A & 10.40 .1 & 4,7 & 4,0 & 3,7 & 3,5 & 5,2 & 27 \\
\hline 44 & 723.4 & 4,6 & 4,0 & 3,9 & 3,9 & 7,3 & 41 \\
\hline 33 & 10.36 .1 & 4,8 & 4,2 & 4,1 & 3,0 & 5,0 & 51 \\
\hline 41 & 11.24 .1 .1 & 4,7 & 4,0 & 3,9 & 4,0 & 7,1 & 51 \\
\hline 28 & 10.8 .2 .1 & 4,6 & 3,6 & 3,4 & 3,5 & 7,1 & 45 \\
\hline 02 & SLP 103.3.2 & 4,7 & 3,9 & 3,8 & 3,6 & 7,0 & 38 \\
\hline 20 & 519 & 4,8 & 4,2 & 4,1 & 4,0 & 6,9 & 55 \\
\hline 21 & 137 & 4,8 & 4,2 & 4,1 & 4,3 & 7,1 & 50 \\
\hline 16 & V 2017 Cuban Dent & 4,6 & 4,2 & 4,1 & 4,0 & 7,2 & 35 \\
\hline 25 & 641.2 & 4,6 & 4,1 & 4,0 & 4,1 & 7,2 & 41 \\
\hline 39 & 11.22.2.3 & 4,6 & 4,0 & 3,9 & 3,8 & 6,9 & 53 \\
\hline 32 & 10.20 .3 .1 & 4,6 & 3,8 & 3,7 & 3,7 & 7,2 & 54 \\
\hline 43 & 124.3 .15 .1 & 4,6 & 3,9 & 3,7 & 4,0 & 7,6 & 42 \\
\hline 42 & 11.30 .1 .1 & 4,7 & 4,0 & 3,9 & 4,0 & 7,3 & 42 \\
\hline 29 & 10.11 .1 .1 & 4,7 & 3,8 & 3,5 & 3,9 & 7,4 & 45 \\
\hline 35 & 11.01 .3 .1 & 4,8 & 3,9 & 3,7 & 3,8 & 7,4 & 61 \\
\hline 34-L & 10.40 .1 & 4,6 & 3,7 & 3,5 & 3,6 & 7,1 & 41 \\
\hline 22 & 531 & 4,6 & 3,9 & 3,9 & 4,1 & 7,4 & 52 \\
\hline $\mathrm{CV}$ da & médias \% & 2,0 & 5,8 & 6,8 & 8,2 & 14,9 & \\
\hline $\bar{x} \pm s($ & & $4,7 \pm 0$ & $1,1 \pm 0$ &, $0 \pm 0$ & $9 \pm 0$ & $3,5 \pm 1,0$ & \\
\hline
\end{tabular}

(1) Volume (ml) de $\mathrm{H}_{2} \mathrm{SO}_{4} 0,1 \mathrm{~N}$ gastos do $13{ }^{\circ}$ ao $20^{\circ}$ dia em soluçăo nutritiva, para baixar o $\mathrm{pH}$ para $5,0-5,5$.

(2) $\mathrm{pH}$ inicial $=5,0$; a partir do $13^{\circ}$ dia em soluçăo nutritiva, o $\mathrm{pH}$ das soluçðes nutritivas foi reajustado entre 5,0 e 5,5 com $\mathrm{H}_{2} \mathrm{SO}_{4} 0,1 \mathrm{~N}$, com exceção da linhagem 37 , cujos reajustes de $\mathrm{pH}$ tiveram ińcio a partir do 150 dia. Os reajustes foram feitos três vezes por semana. 


\title{
4. CONCLUSÕES
}

1. O cultivo de plantas de milho em solução nutritiva com diferentes niveis de $\mathrm{N}$ permitiu definir condições adequadas para a diferenciação e seleção de linhagens mais eficientes na absorção e utilização de nitrogênio.

2. Trinta e nove linhagens, cultivadas em solução nutritiva com $120 \mathrm{mg} /$ litro de $\mathrm{N}$, mostraram variações na produção de matéria seca da parte aérea e das raízes, no conteúdo total de $\mathrm{N}$ e na relação de eficiência (matéria seca produzida por unidade de $\mathrm{N}$ absorvida), que estiveram altamente correlacionadas entre si As linhagens foram classificadas em grupos ineficientes, medianamente eficientes e eficientes na absorção e uso do nitrogênio, com base nos pesos de matéria seca total.

3. O processo de utilização de $\mathrm{N}$ pelas plantas, avaliado mediante a relação de eficiência, revelou-se fator mais significativo que o processo de absorção, no crescimento diferencial das linhagens

\author{
SUMMARY \\ DIFFERENCES IN NITROGEN UPTAKE AND USE OF CORN INBRED LINES \\ GROWN IN NUTRIENT SOLUTIONS
}

\begin{abstract}
Two experiments were conducted in nutrient solutions, in a greenhouse, during the period of October $/ 1982$ to February/1983, in the Experimental Station of Campinas, Instituto Agronomico, State of São Paulo, Brazil. The objective was to study the differences among thirty nine corn (Zea mays L.) in bred lines in relation to $\mathrm{N}$ uptake and use under low $\mathrm{N}$ conditions. At first, five com inbred lines were grown in 2.8 liter pots with different $\mathrm{N}$ levels in the nutrient solutions: $30,60,120,180$ and $240 \mathrm{~N} / \mathrm{liter}$. In a second trial thirty nine inbred lines were tested in nutrient solutions with $120 \mathrm{mg} \mathrm{N} / \mathrm{liter}$, in the same growth system and similar growth conditions. The solutions were continuously aerated and the initial $\mathrm{pH}$ was 5.0 . The $\mathrm{pH}$ was readjusted periodically throughout the experiments. The plants were allowed to grow without $\mathrm{N}$ reposition up to 30 days of age, when $\mathrm{N}$ deficiency symptoms appeared in the leaves. Differences among lines were observed for top and root dry matter yields, for $\mathbf{N}$ concentrations, $\mathbf{N}$ contents, and efficiency ratios (dry matter produced per unit $\mathbf{N}$ absorbed). The $\mathbf{N}$ contents and the efficiency ratios averages followed, proportionally, the variation observed for dry matter yields, with correlation coefficients (r) of 0.87 and 0.92 , and coefficients of variation of means (CV) of 8.7 and $16.1 \%$, respectivelly. This indicated that both processes, absorption and use, varied among genotypes, but the mechanism of $\mathrm{N}$ use, appeared to be the main cause for the differential growth of the genotypes. The inbred lines were ranked and classified based on the plant dry matter data.
\end{abstract}

Index terms: nitrogen; corn; efficiency; $\mathbf{N}$ uptake; $\mathbf{N}$ use; nutrient solution; plant selection. 


\section{REFERÊNCIAS BIBLIOGRÁFICAS}

ALAGARSWAMY, G. \& BIDINGER, F.R. Nitrogen uptake and utilization by Pearl Millet (Pennisetum americanum L. Leeke). In: INTERNATIONAL PLANT NUTRITION COLLOQUIUM, 9., Coventry, UK, 1982. Proceedings. p.12-16.

BAKER, D.E.; JARREL, A.E.; MARSHALL, L.E. \& THOMAS, N.I. Phosphorus uptake from soils by corn hybrids selected for high and low phosphorus accumulation. Agronomy Journal, 62:103-106, 1970.

BATAGLIA, O.C.; TEIXEIRA, J.P.F.; FURLANI, P.R.; FURLANI, A.M.C. \& GALLO, J.R. Análise química de plantas. Campinas, Instituto Agronômico, 1983. 48p. (Boletim técnico, 78)

BERNARDO, L.M., CLARK, R.B. \& MARANVILLE, J.W. Effect of nitrate/ ammonium ratios on nutrient solution $\mathrm{pH}$, nitrogen uptake, and drymatter yields of sorghum. Agronomy Abstracts, 74:92, 1982.

C.LARK, R.B. Nutrient solution growth of sorghum and corn in mineral nutrition studies. Journal Plant Nutrition, 5: 1039-1057, 1982.

.\& BROWN. J.C. Differential mineral uptake by maize inbreds. Communications in Soil Science and Plant Analysis, 5:213-227, 1974.

EPSTEIN, E. \& JEFFERIES, R.L. The genetic basis of selective ion transport in plants. Annual Review of Plant Physiology, 15:169-184, 1964.

FLEMING, A.L. Ammonium uptake by wheat varieties differing in Al tolerance. Agronomy Journal, 75:726-730, 1983.

FRANÇA, G.E. de. Differences in dry matter yield and the uptake, distribution and use of nitrogen by sorghum genotypes. Lincoln, University of Nebraska, 1981.95p. Dissertation (Ph.D.)

FURLANI, A.M.C., BATAGLIA, O.C. \& LIMA, M. Eficiência de linhagens de milho na absorção e/ou utilização de fósforo, a baixo nivel, em solução nutritiva. Bragantia, Campinas, 44(1): 129-147, 1985.

GABELMAN, W.H. Genetic potentials in nitrogen, phosphorus and potassium efficiencies. In: WORKSHOP ON PLANT ADAPTATION TO MINERAL STRESS IN PROBLEM SOILS, Beltsville, Maryland, 1976, edited by M.J. Wright - Proceedings. Ithaca, NY, Cornell University Agricultural Experimental Station, 1976. p.205-212.

GERLOFF, G.C. Plant efficiencies in the use of nitrogen, phosphorus and potassium. In: WORKSHOP ON PLANT ADAPTATION TO MINERAL STRESS IN PROBLEM SOILS, Beltsville, Maryland, 1976, edited by M.J. Wright - Proceedings. Ithaca, NY, Cornell University Agricultural Experimental Station, 1976. p.161-173. 
HIATT, A.J. \& LEGGETT, J.E. Ionic interactions and antagonism in plants. In: CARLSON, E.W., ed. The plant root and its environment. Charlottesville, University Press of Virginia, 1974. p.101-134.

HUCKLESBY, D.P.; BROWN, C.M.; HOWELL, S.E. \& HAGEMAN, R.H. Late spring applications of nitrogen for efficient utilization and enhanced production of grain and protein of wheat. Agronomy Journal, 63:274$277,1971$.

LINDGREN, D.T.; GABELMAN, W.H. \& GERLOFF, G.C. Variability of Phosphorus uptake and translocation in Phaseolus vulgaris L. under phosphorus stress. Journal ot the American Society for Horticultural Science, 102:674-677, 1977.

MARANVILLE, J.W.; CLARK, R.B. \& ROSS, W.M. Nitrogen efficiency in grain sorghum. Journal of Nutrition, 2(5):577-589, 1980.

NIELSEN, N.E. \& BARBER, S.A. Differences among genotypes of corn in the kinetics of P uptake. Agronomy Journal, 70:695-698, 1978.

O'SULLIVAN, J.; GABELMAN, W.H. \& GERLOFF, G.C. Variations in efficiency of nitrogen utilization in tomatoes (Lycopersicum esculentum Mill.) grown under nitrogen stress. Journal of the American Society for Horticultural Science, 99:543-547, 1974.

POLLMER, W.G.; EBERHARD, D.; KLEIN, D. \& DHILLON, B.S. Genetic control of nitrogen uptake and translocation in maize. Crop Science, 19(1):82-86, 1979. 